\title{
Comparative Study between Pediatric Spinal and Caudal Anesthesia
}

\author{
Dr. Naitik Patel ${ }^{1}$, Dr. Mandakinee Thacker ${ }^{2}$ \\ ${ }^{1,2}$ Assistant Professor, Department of Anaesthesia, Gujarat Adani Institute of Medical Science, Bhuj, Gujarat.
}

\begin{abstract}
Introduction: Regional anesthesia in children was first studied by August Bier in 1899. Since then, spinal anesthesia was known to be practiced for several years with a series of cases published as early as in 1909-1910. The appearance of neuromuscular blocking agents and the development of volatile anesthetics in the forties shifted the techniques toward general anesthesia. Material \& Method: All the study patients were examined on previous day of the surgery \& all routine investigations were noted. All the patients were kept nil by mouth for 6 hours before the surgery. Patient's guardian or the parents were informed about anesthetic procedure and the informed consent was taken. Result \& Conclusion: In the present study the effectiveness of the caudal anesthesia was compared with the spinal anesthesia. The dosage was taken as per $\mathrm{mg} / \mathrm{kg}$ for producing adequate anesthesia as per the guidance provided in the different other studies but different authors.
\end{abstract}

Keywords: Regional, Spinal, Caudal anesthesia

\section{Introduction}

Caudal anesthesia was first described at the turn of last century by two French physicians, FernandCathelin and Jean-AnthanaseSicard. The technique predated the lumbar approach to epidural block by several years. ${ }^{1}$ Caudal anesthesia is one of the most used-popular regional blocks in children. This technique is a useful adjunct during general anesthesia and for providing postoperative analgesia after infraumbilical operations. The quality and level of the caudal blockade is dependent on the dose, volume, and concentration of the injected drug. Although it is a versatile block, one of the major limitations of the single-injection technique is the relatively short duration of postoperative analgesia. ${ }^{2}$ The most frequently used method to further prolong postoperative analgesia following caudal block is to add different adjunct drugs to the local anesthetics solution. Only few studies evaluated quality and duration of caudal block against the volume of the local anaesthetic applied. After reviewing recent scientific literature, the authors compare the duration of postoperative analgesia in children scheduled for intraumblical surgery. ${ }^{3}$

Regional anesthesia in children was first studied by August Bier in 1899. Since then, spinal anesthesia was known to be practiced for several years with a series of cases published as early as in 1909-1910. ${ }^{4}$ The appearance of neuromuscular blocking agents and the development of volatile anesthetics in the forties shifted the techniques toward general anesthesia. However, spinal pediatric anesthesia did not disappear. The first publication that mentions this technique in children was written by Campbell in 1933 and the second one by Leigh and Belton in 1951. The caudal technique is extensively described by Key in $1994 .{ }^{5}$ When regional anesthesia is given to older children, some variables such as the intervention site, age, and presence of chronic disease, cooperativeness and parental preferences should be considered. In present study we compared caudal block with spinal block in pediatric patients. ${ }^{4}$
Hence the aim of the study was to conducted to compare the technique regarding onset of block, level of block and duration of analgesia. The written informed consent was obtained from all parents whose children were participated in this study. Patient' selection: 100 children of Age 5 to 15 year, weighing less than $30 \mathrm{~kg}$, of both sex, undergoing elective infra umbilical surgery. Exclusion criteria: patient with the history or evidence of infection at back, allergy to drugs, congenital malformation of the back, preexisting neurological or spinal diseases.

\section{Material \& Method}

All the study patients were examined on previous day of the surgery \& all routine investigations were noted. All the patients were kept nil by mouth for 6 hours before the surgery. Patient's guardian or the parents were informed about anesthetic procedure and the informed consent was taken. In the operation theatre intra-venous line was secured $\&$ injection isolyte-p was started. Standard monitors like ECG, PULSE OXIMETER \& NIBP were applied \& baseline parameters were recorded. All children were pre medicated intravenously with injection glycopyrrolate 0.04 $\mathrm{mg} / \mathrm{kg} \&$ injection midazolam 0.05 to $0.1 \mathrm{mg} . / \mathrm{kg}$. Before performing procedure, injection ketamine $2 \mathrm{mg} / \mathrm{kg}$ was given. Hundred patients were divided into two groups.

Group A (Caudal block): - 50 patients were given caudal block with full aseptic precaution in left lateral position. Drug- $0.5 \%$ plain bupivacaine $2 \mathrm{mg} / \mathrm{kg}$ plus normal saline. Volume $=0.1 \mathrm{ml}$ of anesthetic solution $\mathrm{X}$ body weight $\mathrm{X}$ number of spinal segments to be blocked

Group B (Spinal block): - 50 patients were given spinal block with full aseptic precaution in left lateral position. Drug- $0.5 \%$ plain bupivacaine $0.4 \mathrm{mg} / \mathrm{kg}$. Total $0.08 \mathrm{ml} / \mathrm{kg}$ anesthetic solution was injected.

After performing the procedure, patients were turned into supine position; the level of block was checked by the pin prick method up to the 10 minutes. Motor block was assessed by Bromage scale. Heart rate, blood pressure, 


\section{International Journal of Science and Research (IJSR) \\ ISSN (Online): 2319-7064 \\ Index Copernicus Value (2013): 6.14 | Impact Factor (2014): 5.611}

respiratory rate were monitored every 10 minutes during the first 45 minutes and then every 25 minutes during surgery. Decrease in $\mathrm{MAP}>30 \%$ was defined as hypotension \& treated with intravenous fluids or inj. ephedrine. A decrease in $\mathrm{HR}>30 \%$ was defined as bradycardia\& treated with intravenous inj. Atropine $0.01 \mathrm{mg} / \mathrm{kg}$. During surgery, sedation is maintained using midazolam at $0.1 \mathrm{mg} / \mathrm{kg}$ as necessary and the patient is kept with continuous oxygen administration by a mask close to the face. Postoperatively pain was assessed every 45 minutes using observed pain score. Duration of analgesia *(time from block to first dose of rescue analgesic or OPS $>=12$ ) were recorded. Statistical analysis was done using SPSS software. Data was expressed as mean and standard deviation; Data were compared using analysis of variance ${ }^{6}$. $\mathrm{P}$ value $<0.05$ was considered statistically significant.

\section{Results}

Table 1: Bromage Criteria

\begin{tabular}{|c|c|c|}
\hline Score & Criteria & Degree of Block \\
\hline 0 & $\begin{array}{c}\text { Free movements of legs feet-raise } \\
\text { extended legs. }\end{array}$ & None \\
\hline 1 & $\begin{array}{c}\text { Inability to raise extended leg, knee } \\
\text { flexion decreased but full flexion at } \\
\text { ankle and feet present }\end{array}$ & $33 \%$ (partial) \\
\hline 2 & $\begin{array}{c}\text { Inability to raise legs or flex knees, } \\
\text { flexion at ankle and feet present }\end{array}$ & $66 \%$ (partial) \\
\hline 3 & $\begin{array}{c}\text { Inability to raise legs, flex knees or } \\
\text { ankle or move toes }\end{array}$ & Complete paralysis \\
\hline
\end{tabular}

Table 2: Data table

\begin{tabular}{|c|c|c|c|}
\hline & Group A & Group B & P Value \\
\hline Number of patient & 50 & 50 & 1 \\
\hline Sex (m:f) & $30: 20$ & $33: 17$ & 0.67 \\
\hline ASA I \& II & $28: 22$ & $31: 19$ & 0.53 \\
\hline Age & 7 & 5 & 0.65 \\
\hline Weight & 14.5 & 15.5 & 0.55 \\
\hline
\end{tabular}

Demographics were comparable in all the groups, however in both the groups male were selected more as per the surgeries were male specific.

Table 3: level of block

\begin{tabular}{|l|l|l|}
\hline & Group A & Group B \\
\hline Sensory level & T8 \pm 2 segment & T6 \pm 2 segment \\
\hline
\end{tabular}

The level of anaesthesia block was given T8 level in group A and for Group B it was T6 level

\section{Discussion}

In 1983, in the American Society of Anesthesiologists Regional Anesthesia Breakfast Panel, Abajian et al started the "frenzy" of modern paediatric spinal anaesthesia when they reported 78 cases in 81 infants. $^{7}$ The textbook of paediatrics by Leigh and Belton also demonstrated that $10 \%$ of all anaesthetic procedures practiced in children at the Vancouver General Hospital were spinal techniques, including pulmonary lobectomies and pneumonectomies. However, paediatric spinal anaesthesia never achieved its popularity because of continuous discoveries of newer and better volatile agents and muscle relaxants for general anaesthesia. $^{8}$

Spinal anaesthesia has the advantage that profound nerve block can be produced in a large part of the body by the relatively simple injection of a small amount of local anaesthetic. ${ }^{9}$ However, the greatest challenge in spinal anaesthesia is to control the spread of local anaesthetic through the cerebrospinal fluid (CSF) to provide a block which is adequate for the proposed surgery without unnecessary extensive spread, and increased risk of complications. $^{10}$

In the present study the effectiveness of the caudal anesthesia was compared with the spinal anesthesia. The dosage was taken as per $\mathrm{mg} / \mathrm{kg}$ for producing adequate anesthesia as per the guidance provided in the different other studies but different authors. The dose and volume of the anesthetic solution were sufficient enough to keep the effect of solution long enough that the surgeon could perform the surgery without facing any complications. The dosage level was kept by keeping toxicity in mind.

Onset of sensory block in caudal was delayed then spinal block that was $7 \pm 3.5$ in caudal and $2.5 \pm 1.2$ minutes. while that comparing the duration of analgesia was longer with caudal $(140 \pm 10)$ than the spinal $(85 \pm 10)$. However as the age and weight of the patient decreases; duration of both the block tend to decreases.

The changes in the systolic, diastolic and the mean blood pressures were minimal to negligible. This is because sympathetic vascular tone at rest in the children is less than in adults. Heart rate was kept at the normal range because regional anesthesia do eliminates the Brady cardiac response. Respiratory rate and pulse oximetry did not suffer much significant changes, which is coincident with other authors.

Age, weight and sex were not the limiting factors for the administration of the techniques. Age range was 3 to 15 years and weight range was $8 \mathrm{~kg}$ to $30 \mathrm{~kg}$. We did observed that; younger the patient the more effective is the anesthesia. There were fewer changes in arterial pressure and heart rate. No other types of complications were observed. No local infections occurred probably because of the careful and aseptic cleansing done before the punctures.

\section{Conclusion}

We could conclude that the described techniques were used successfully. Both the techniques have different indications; depending on type and duration of surgery. Other most important factors to be considered are the skills and experience of the anesthesiologist with the particular technique, the available anesthetics and the necessary material for either technique.

\section{References}

[1] Candido KD, Winnie A: Caudal anesthesia. Textbook of regional anesthesia and acute pain management New York: McGraw Hill 2007:269-84.

\section{Volume 4 Issue 12, December 2015}




\section{International Journal of Science and Research (IJSR) \\ ISSN (Online): 2319-7064}

Index Copernicus Value (2013): 6.14 | Impact Factor (2014): 5.611

[2] El-Maksoud OMEA, El-Hamid AMA, Mosaad AA: Comparative Study of Neostigmine and Ketamine as Additives to Plain Bupivacaine in Caudal Analgesia after Lower Abdominal Surgery in Pediatrics.

[3] Silvani P, Camporesi A, Agostino M, Salvo I: Caudal anesthesia in pediatrics: an update. Minerva anestesiologica 2006, 72:453-9.

[4] Pandya C, Mehta K, Patel K, Panchasara K: Associate Professor,** Professor,*** 2nd year resident Dept of Anesthesia, Smt NHL Municipal Medical College, Ahmedabad.

[5] Brown T: History of pediatric regional anesthesia. Pediatric Anesthesia 2012, 22:3-9.

[6] Volkova L, Khalif I, Kabanova I: [Impact of the impaired intestinal microflora on the course of acne vulgaris]. Klinicheskaia meditsina 2000, 79:39-41.

[7] Goyal R, Jirtjil K, Baj B, Singh S, Kumar S: Paediatric spinal anesthesia. Indian Journal of Anaesthesia 2008, 52:264.

[8] Barash PG: Clinical anesthesia: Lippincott Williams \& Wilkins, 2009.

[9] Flecknell P: Laboratory animal anaesthesia: Academic Press, 2009.

[10] AbdElBarr T, Elshalakany NA, Shafik YM: Single dose spinal analgesia: Is it a good alternative to epidural analgesia in controlling labour pain? Egyptian Journal of Anaesthesia 2014, 30:241-6. 